Article

\title{
The Influence of Nanoparticles' Conductivity and Charging on Dielectric Properties of Ester Oil Based Nanofluid
}

\author{
Konstantinos N. Koutras ${ }^{1, *} \mathbb{C}$, Ioannis A. Naxakis ${ }^{1} \mathbb{D}$, Eleftheria C. Pyrgioti ${ }^{1, *}$, \\ Vasilios P. Charalampakos ${ }^{2}$, Ioannis F. Gonos ${ }^{3} \mathbb{D}$, Aspasia E. Antonelou ${ }^{4}$ and \\ Spyros N. Yannopoulos 4 (D) \\ 1 High Voltage Laboratory, Department of Electrical \& Computer Engineering, University of Patras, \\ 26500 Patras, Greece; naxakis@ece.upatras.gr \\ 2 Department of Electrical \& Computer Engineering, University of the Peloponnese, 26334 Patras, Greece; \\ charalambakos@uop.gr \\ 3 School of Electrical \& Computer Engineering, National Technical University of Athens, \\ 15780 Athens, Greece; igonos@cs.ntua.gr \\ 4 Foundation for Research and Technology Hellas, Institute of Chemical Engineering Sciences, \\ 26504 Patras, Greece; antonelou@iceht.forth.gr (A.E.A.); sny@iceht.forth.gr (S.N.Y.) \\ * Correspondence: k.koutras@ece.upatras.gr (K.N.K.); e.pyrgioti@ece.upatras.gr (E.C.P.)
}

Received: 13 November 2020; Accepted: 9 December 2020; Published: 11 December 2020

check for updates

\begin{abstract}
This study addresses the effect of nanoparticles' conductivity and surface charge on the dielectric performance of insulating nanofluids. Dispersions of alumina and silicon carbide nanoparticles of similar size $(\sim 50 \mathrm{~nm})$ and concentration $(0.004 \% w / w)$ were prepared in natural ester oil. The stability of the dispersions was explored by dynamic light scattering. AC, positive and negative lightning impulse breakdown voltage, as well as partial discharge inception voltage of the nanofluid samples were measured and compared with the respective properties of the base oil. The obtained results indicate that the addition of $\mathrm{SiC}$ nanoparticles can lead to an increase in $\mathrm{AC}$ breakdown voltage and also enhance the resistance of the liquid to the appearance of partial discharge. On the other hand, the induction of positive charge from the $\mathrm{Al}_{2} \mathrm{O}_{3}$ nanoparticles could be the main factor leading to an improved positive Lightning Impulse Breakdown Voltage and worse performance at negative polarity.
\end{abstract}

Keywords: nanofluid; conductivity; alumina nanoparticles; silicon carbide; AC breakdown; lightning impulse breakdown; partial discharge

\section{Introduction}

The lifetime of the power transformer is a major factor for the reliability and uninterrupted operation of the electricity grid. Liquid insulation, as well as the paper immersed in dielectric liquid, should provide protection of its windings under the influence of electrical, thermal, and even environmental effects to prevent short circuits and leakage currents [1,2]. The mineral oil typically used as dielectric and thermal coolant has certain disadvantages, such as toxicity, high flammability, and reduced lifetime [3-7]. Therefore, the first step towards the improvement of transformer insulation is to turn the attention of research to the study of alternatives, such as natural or synthetic ester oils [7-10]. The use of ester oils entails, beyond improved properties like biodegradability and higher moisture tolerance, benefits for the transformer itself, essentially aging characteristics, enhanced lifetime, and loading capability [3,11,12]. 
Nanotechnology has already been used for various subsurface applications [13-16]. In liquid insulation, the integration of nanoparticles (NPs) in a base conventional oil volume has been part of recent research in an effort to achieve enhanced dielectric and thermal performance with optimum insulation quantity to recede the size of the transformer [17]. The term "nanofluid" (NF) was firstly proposed by Choi et al. [18], indicating a mixture where both the NPs and the base oil contribute to the application providing enhanced thermal conductivity. Since then, a number of reports have appeared in the literature regarding the integration of many different types of NPs in mineral or ester oils achieving improvement not only in thermal but also in dielectric properties based on their type, concentrations, shapes, and sizes [1-9,19-22].

It has been noticed that the addition of nitrides mainly leads to improvement of thermal properties [20,21], while Thomas et al. [3] indicated that the integration of $\mathrm{CaCu}_{3} \mathrm{Ti}_{4} \mathrm{O}_{12} \mathrm{NPs}$ in $0.050 \%$ vol. concentration could lead to thermal conductivity enhancement of the synthetic ester oil by $10 \%$ at room temperature. The integration of metal oxides, on the other hand, could have beneficial effect on dielectric ones. Towards this direction, Zhong et al. [8] and Du et al. [2,22] have reported improvement of AC and Lightning Impulse Breakdown characteristics following the addition of semi-conductive NPs in natural ester and mineral oil volumes, respectively. The addition of magnetic $[4,23]$ and dielectric $[19,23,24] \mathrm{NPs}$, even at low weight fractions, has also shown increase in the dielectric strength with respect to the base oil. Khaled et al. [23] studied the effect of conductive $\mathrm{Fe}_{3} \mathrm{O}_{4}$, and dielectric $\mathrm{Al}_{2} \mathrm{O}_{3}$ and $\mathrm{SiO}_{2} \mathrm{NPs}$ on $\mathrm{AC}$ breakdown voltage (AC BDV) of synthetic ester oil reporting $48 \%$ improvement with the addition of conductive $\mathrm{Fe}_{3} \mathrm{O}_{4} \mathrm{NPs}(50 \mathrm{~nm})$ at a concentration of $0.4 \mathrm{~g} / \mathrm{L}$, while the integration of insulating $\mathrm{Al}_{2} \mathrm{O}_{3} \mathrm{NPs}$ of $13 \mathrm{~nm}$ size at a concentration of $0.05 \mathrm{~g} / \mathrm{L}$ led to a $35 \%$ improvement. Last but not least, the viscosity of the oil is also affected based on the type and the loading of the NPs inside the matrix. Fontes et al. [25] reported a $25 \%$ rise in viscosity adding diamond NPs in transformer oil at 0.050 vol.\%. Ilyas et al. [26] concluded that the dynamic viscosity of the mineral oil-based alumina NFs had decreased with the rise of temperature.

With regard to the mechanisms leading to the beneficial effects of the NPs on the aforementioned properties, a number of theories have been proposed [27-29]. Most of them consider the operation of NPs as "electron traps" under the application of an external electric field hindering the streamer propagation between the electrodes, adopting different explanations $[27,28]$. Conductive NPs can capture the fast electrons in shallow traps through charge induction $[27,28]$. Semi-conductive and dielectric NPs could have the same effect as the conductive ones, because they are polarized under the influence of an external electric field.

Despite the number of publications devoted to the study of the metal oxide NPs' effect on dielectric and thermal properties of the transformer oil, there is limited literature concerning the influence of metal carbides in transformer oils, although they are widely used in other industrial sectors. The main contribution of this article is to compare the dielectric performance of insulating $\mathrm{Al}_{2} \mathrm{O}_{3}$ and semi-conducting SiC-ester based NFs in terms of AC breakdown voltage (AC BDV), positive and negative Lightning Impulse breakdown voltage (LI BDV) and partial discharge (PD) activity. The choice of these specific types of NPs, having similar nominal size, is based on the fact that they have similar permittivities, therefore conductivity should play a major role in the dielectric performance of the corresponding NFs.

In this study, insulating alumina and semi-conducting SiC NPs were dispersed into natural ester oil Envirotemp ${ }^{\mathrm{TM}} \mathrm{FR} 3^{\mathrm{TM}}$ in concentration of $0.004 \% w / w$. The choice of this particular concentration is based on previous work [30]. After the preparation of the NF samples, dynamic light scattering was used to assess their agglomeration behavior in the dispersions. AC, positive and negative LI $\mathrm{BDV}$, as well as PDIV, have been measured, analyzed, and compared to the base oil's characteristics in an effort to conclude about their effect on dielectric performance of transformer oil. The results of the conducted measurements have indicated that the NF-containing SiC NPs possesses improved dielectric properties which is attributed to the higher conductivity of these NPs with respect to the $\mathrm{Al}_{2} \mathrm{O}_{3} \mathrm{NPs}$ for the same nominal size and weight percentages. 


\section{Materials and Methods}

This section includes the steps followed for the preparation of NF dispersions and the experiments undertaken for the study the stability and the conduction of measurements of dielectric properties.

Envirotemp ${ }^{\mathrm{TM}}$ FR3 ${ }^{\mathrm{TM}}$, purchased by Cargill, was used as matrix. It is a renewable, bio-based natural ester dielectric coolant, which is formulated from seed oils and performance enhancing additives with a density of $0.92 \mathrm{~g} \cdot \mathrm{cm}^{-3}$ at $20^{\circ} \mathrm{C}$, relative permittivity 3.2 , conductivity $5 \times 10^{-14} \mathrm{~S} \cdot \mathrm{m}^{-1}$, and flash and fire points greater than 250 and $300^{\circ} \mathrm{C}$, respectively. The commercially obtained dielectric alumina and semi-conducting SiC NPs were used as received without any further treatment. These NPs were selected considering their similar nominal size and permittivities. Some of the most important dielectric and thermal properties of the NPs are presented in Table 1.

Table 1. Dielectric and thermal properties of the NPs.

\begin{tabular}{ccc}
\hline Property & $\mathbf{A l}_{\mathbf{2}} \mathbf{O}_{\mathbf{3}}$ & $\mathrm{SiC}$ \\
\hline Nominal average diameter $(\mathrm{nm})$ & 50 & 50 \\
Relative permittivity & 9.8 & 9.7 \\
Conductivity $\left(\mathrm{S} \cdot \mathrm{m}^{-1}\right)$ & $10^{-12}$ & $3.16 \times 10^{-3}$ \\
Thermal Conductivity $\left(\mathrm{W} \cdot \mathrm{m}^{-1} /{ }^{\circ} \mathrm{C}\right.$ at $\left.25^{\circ} \mathrm{C}\right)$ & 25.5 & 350 \\
\hline
\end{tabular}

\subsection{Preparation of Nanofluid Samples}

A two-step method was implemented for the production of NF samples. Primarily, a volume of $500 \mathrm{~mL}$ of FR3 ${ }^{\mathrm{TM}}$ was picked as base oil for the formation of NFs. Each matrix sample was filtered and dried in hot air oven at $120^{\circ} \mathrm{C}$ overnight in order to achieve moisture reduction within the prescribed limits. The level of moisture within each sample after drying was confirmed with Karl Fischer titration method, following the procedure reported elsewhere [31]. In brief, Mitsubishi Chemicals Co. CA-100 moisture meter and Metrohm KF Coulometer 831 measured and confirmed, respectively, that the remaining moisture was below the recommended values.

Subsequently, $18.4 \mathrm{mg}$ of the two types of NPs under study were immersed in appropriate base oil volumes to achieve the desired $w / w$ concentration. As NPs have high surface areas $[1,32,33]$ they tend to agglomerate shortly after their addition in the matrix forming clusters, where primary particles are held together by van der Waals interaction forces [32,33].

In order to avoid the agglomeration of NPs, which diminishes their beneficial effects on dielectric strength $[1,7,32,33]$, each mixture was subjected to ultrasonication and vigorous magnetic stirring to achieve good dispersion of the NPs and homogenization of the final NF samples. In fact, each sample was sonicated for $30 \mathrm{~min}$ with the assistance of a Raypa UCI-50 ultrasonic bath, followed by a $15 \mathrm{~min}$ stirring with the use of a Biosan MSH-300 magnetic stirrer. The maximum input power of the sonicator is about $300 \mathrm{~W}$ with a frequency of $35 \mathrm{kHz}$. Each NF sample was subjected to ultrasonication under full power and the amount of ultrasonication energy was in the range of $540 \mathrm{~kJ}$. This cycle was repeated three times for both NF samples, ensuring uniform dispersion of the colloidal suspensions, as indicated in [7]. Table 2 depicts the labeling of the NF samples, as well as the base oil, which will be submitted in the same experiments as well, while images of the two NF samples are shown in Figure 1 immediately after their preparation.

Table 2. Details of nanofluids studied in this work.

\begin{tabular}{cc}
\hline Sample Name & NPs Concentration $(\% \boldsymbol{w} / w)$ \\
\hline Base & 0 \\
iNF & NF with $0.004 \% \mathrm{Al}_{2} \mathrm{O}_{3} \mathrm{NPs}$ \\
$\mathrm{sNF}$ & $\mathrm{NF}$ with $0.004 \% \mathrm{SiC} \mathrm{NPs}$ \\
\hline
\end{tabular}




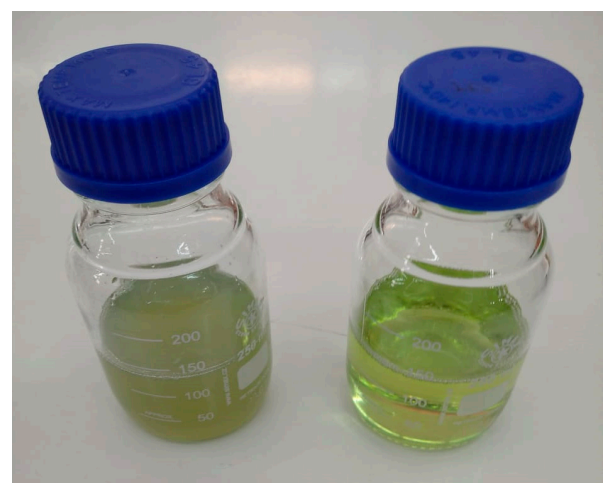

Figure 1. The NF samples shortly after their synthesis: sNF left; iNF right.

\subsection{Experimental Part}

There are two major categories, according to which the dielectric measurements regarding any High Voltage (HV) equipment are classified: the destructive and non-destructive tests. In the context of the destructive tests, AC, positive and negative LI BDV are measured for the two NF samples along with a base oil sample. In regard to the non-destructive ones, PDIV, as well as the variation of the apparent charge for various voltage levels, have been measured.

$\mathrm{AC} B D V$ is the fundamental parameter for the characterization of any insulation system, as long the transformer nominally operates under AC voltage. For the determination of this property, each one of the samples under investigation is stressed under AC voltage/ $60 \mathrm{~Hz}$ using a Baur DTA $100 \mathrm{C}$ generator, as illustrated in Figure 2a, according to the conditions of IEC 60,156 standard. The generator can produce up to $100 \mathrm{kV}$ increasing the voltage at a rate of $2 \mathrm{kV} / \mathrm{s}$ until breakdown occurs between two Rogowski electrodes, which ensure a uniform electric field distribution, with the gap distance set at $2.5 \mathrm{~mm}$. At the beginning of the experimental procedure, the electrodes are polished and cleaned. 10 sets of 6 breakdown events ( 60 in total) are performed, with the applied interval being 2 min between two successive breakdowns and $5 \mathrm{~min}$ between two sets. The results are fit to Weibull and normal distributions in order the AC BDV in low probability levels to be estimated $[7,23,34]$.

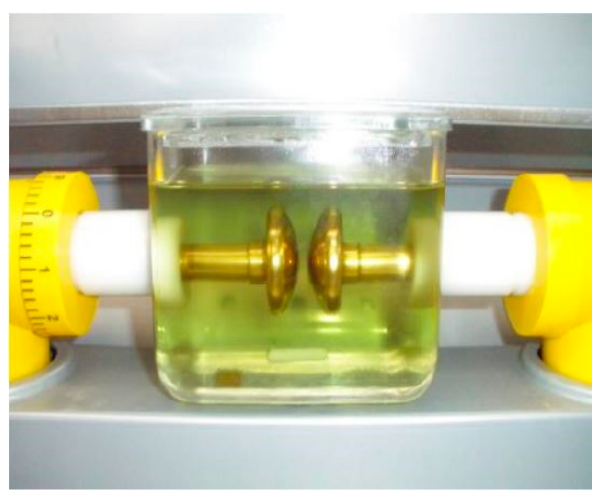

(a)

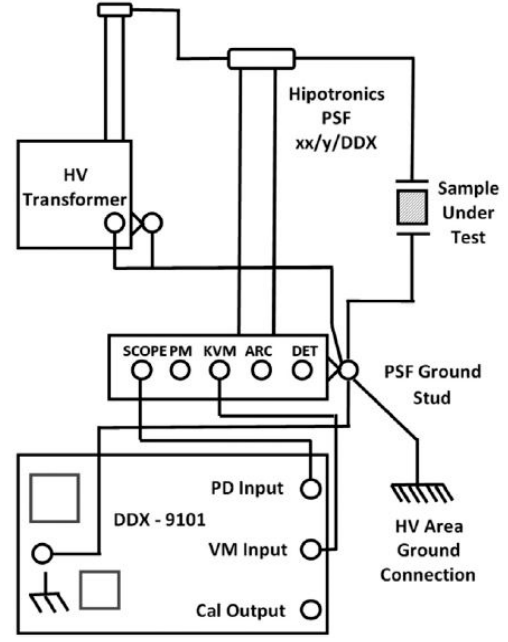

(b)

Figure 2. AC BDV and PD apparatuses: (a) BAUR DTA test cell with Rogowski electrodes. (b) Schematic diagram of the PD setup.

Regarding the measurement of LI BDV, this is another property of major importance as it is an indication for the strength of the insulation in emergency conditions, such as lightning strikes. 
A two-stage impulse generator is used, producing up to $400 \mathrm{kV}$, with positive and negative polarity, according to IEC 60,897 standard. A point-sphere geometry is used, ensuring a highly divergent field geometry, with the gap distance set at $25 \mathrm{~mm}$. The radius of curvature is $50 \mu \mathrm{m}$, while the diameter of the sphere is $12.7 \mathrm{~mm}$. Five voltage applications are conducted for each voltage level with each sample being replaced with a new one after every BD event, ensuring a good reliability for the processing of the results. The applied lightning impulse voltage $1.2 / 50 \mu \mathrm{s}$, is monitored on oscilloscope Tektronix DPO4104; $1 \mathrm{GHz} / 5 \mathrm{GS}$ s-1.

In terms of the conduction of PD measurements, a HV test transformer (HIGH VOLT GmbH Transformer PEOI 40/100,100 kV) is used with a TETTEX Instruments PD Detector DDX-9101 to measure the apparent charge to a nominal capacitor (HIPOTRONICS capacitor PSF 100-1). The schematic diagram of the configuration is displayed in Figure 2b. The test cell consists of two plate electrodes with the gap between them set at $0.75 \mathrm{~mm}$. Nomex ${ }^{\circledR}$ Dupont ${ }^{\mathrm{TM}}$ insulating paper with $0.75 \mathrm{~mm}$ thickness impregnated to the NFs and base oil samples, is put in the gap. The AC voltage value for which the measured apparent charge exceeds the value of $10 \mathrm{pC}$ is considered as the PDIV for each sample under investigation. The insulating papers impregnated to iNF, sNF, and base oil samples are stressed under AC voltage while the transformer is increasing the voltage at a rate of $0.1 \mathrm{kV} / \mathrm{s}$ until the measured apparent charge exceeds the threshold value. Each experiment is repeated 4 times for ensuring the reliability of the obtained results.

\section{Results}

\subsection{Particle Size and Agglomeration Dynamics in Dispersions}

Field emission scanning electron microscopy (FE-SEM) was used to study the particle size and particle size distribution of the dry powders. The NPs were drop-casted by ethanol dispersion onto $\mathrm{Si}$ substrates. Figure 3 illustrates typical images of the $\mathrm{Al}_{2} \mathrm{O}_{3}$ Figure $3 \mathrm{a}$ and $\mathrm{SiC}$ particles Figure $3 \mathrm{~b}$ at high magnifications. For both samples, the particles seem agglomerated, as it typically occurs when particles are drop casted from a dispersion to the substrate. The images reveal that the particles sizes have the nominal values, being, in particular, $\sim 45-50 \mathrm{~nm}$ in the case of $\mathrm{SiC}$ and in the range $30-35$ for $\mathrm{Al}_{2} \mathrm{O}_{3}$. For both materials, image analysis over broader areas by FE-SEM, incorporating a larger number of primary particles, show very narrow particle size distributions.
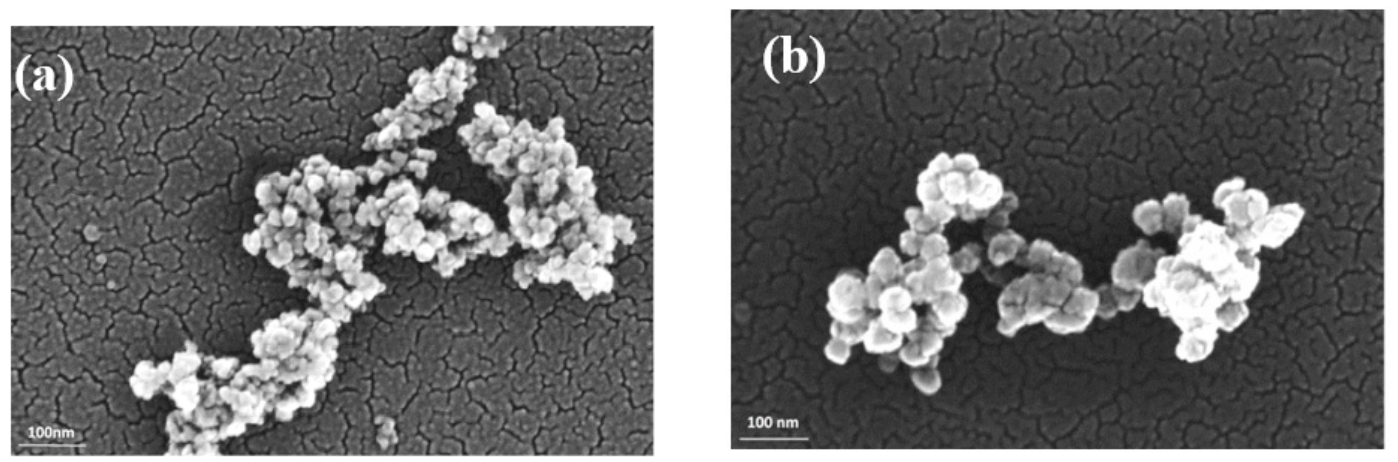

Figure 3. Representative FE-SME images of (a) $\mathrm{Al}_{2} \mathrm{O}_{3}$ and (b) $\mathrm{SiC}$ NPs at high magnification.

The dynamics of NPs in dispersion are of paramount importance since their agglomeration rate essentially determines the high-performance lifetime of the NF. DLS is a versatile technique able to provide the rate of agglomeration process in situ. Apart from the primary particle size, the technique can sensitively furnish information on the formation of small agglomerates ad their evolution upon aging. Details about the method and data analysis applied to a similar system, namely, a $\mathrm{TiO}_{2}$-based $\mathrm{NF}$, have been presented elsewhere [7]. Figure 4 shows the hydrodynamic radii of the two NFs measured at two different times, immediately after their dispersion preparation and after 5 days. The $R_{h}$ data reveal that for each NF there are two different population of particles. One population with $R_{h}$ around 
$40 \mathrm{~nm}$ is related to the dynamics of the primary NPs, while agglomerates with $\mathrm{R}_{\mathrm{h}}$ of few hundreds of $\mathrm{nm}$ also exist in the dispersions.

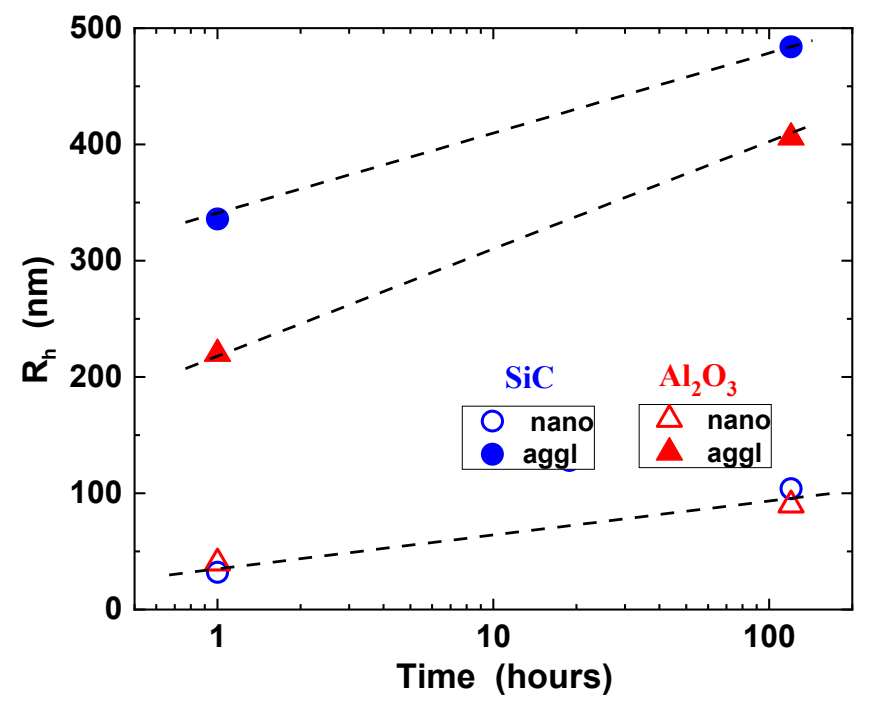

Figure 4. Hydrodynamic radii estimated by DLS data in dispersion, measured at short and long times after the dispersion preparation.

The evolution of $\mathrm{R}_{\mathrm{h}}$ against time show that a weak agglomeration, in relation to $\mathrm{TiO}_{2}$-based oil dispersion [7] takes place. Both the primary particles (nano) and their agglomerates (aggl) exhibit an increase in size following similar rates among the two types of NPs. These findings demonstrate that the proclivity toward agglomeration of $\mathrm{SiC}$ and $\mathrm{Al}_{2} \mathrm{O}_{3}$ is rather weak, e.g., compared to $\mathrm{TiO}_{2} \mathrm{NFs}$. This finding lends support to the accuracy of the electrical characterization, considering that possible fast agglomeration process may affect the accurate monitoring of electrical parameters.

\subsection{AC Breakdown Voltage}

According to the mean AC BDVs displayed in Figure 5 and Table 3, iNF and sNF samples present enhanced dielectric strength by $4.1 \%$ and $16.3 \%$, respectively. The standard deviation of the collected AC BDV events is approximately the same for the iNF with respect to that of the base oil. On the contrary, the standard deviation of the results regarding SNF is increased.

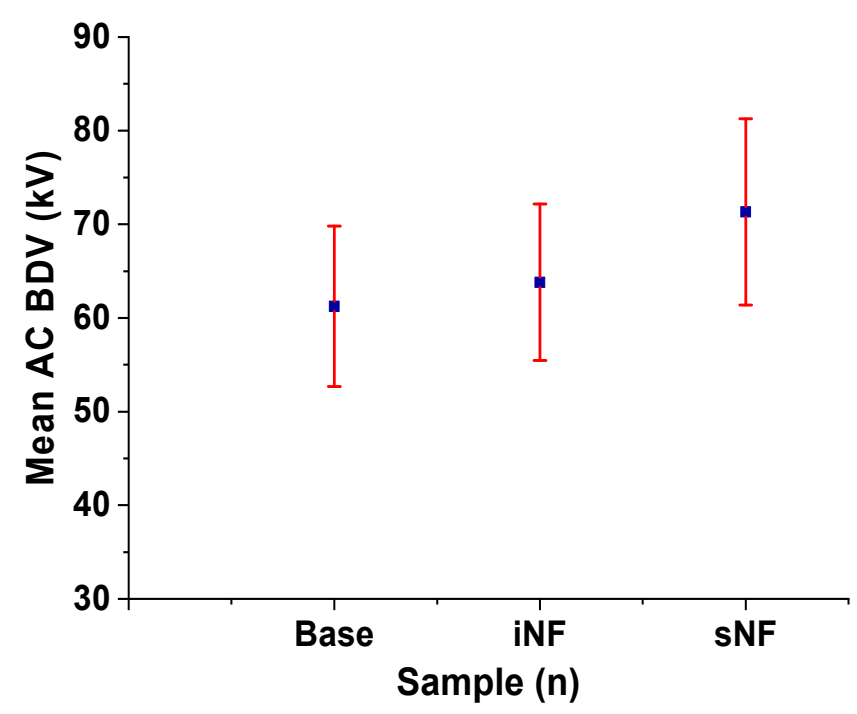

Figure 5. Mean AC BDVs and standard deviation of the NF and base oil samples. 
Table 3. Descriptive statistics of the compared samples.

\begin{tabular}{ccccc}
\hline Sample Name (n) & Mean BDV (kV) & Standard Deviation $\mathbf{( k V )}$ & Scale & Shape \\
\hline Base & 61.3 & 8.5 & 8.7 & 64.8 \\
iNF & 63.8 & 8.3 & 8.9 & 67.4 \\
sNF & 71.3 & 9.9 & 8.5 & 75.5 \\
\hline
\end{tabular}

The estimation of the BDV in low probability levels is of major importance as well. The BDV can be considered as a random variable that follows normal or/and Weibull distribution [7,33-36]. The cumulated distribution functions (CDF) of the normal and Weibull random variable $x$, expressing the breakdown voltage, are given by (1) and (2), respectively:

$$
\begin{gathered}
F_{(x)}=\frac{1}{2}\left[1+\operatorname{erf}\left(\frac{x-\mu}{\sigma \sqrt{2}}\right)\right] \\
F_{(x)}=1-e^{-\frac{x}{\beta} \alpha}
\end{gathered}
$$

where, $\mu$ is the mean value; $\sigma$ is the standard deviation; $\alpha$ is the shape parameter and $\beta$ is the scale parameter.

Firstly, Anderson-Darling goodness of fit test is performed to determine whether the sample of the $\mathrm{BD}$ events are normally distributed. The same procedure is followed for Weibull distribution too, because it is expected to give more precise analysis as it does not make assumptions of the skewness and kurtosis. At $5 \%$ significance level, the $\mathrm{p}$-value is higher for all the samples under investigation both for normal and Weibull distribution, as shown in Table 4.

Table 4. Goodness of fit test (Anderson-Darling).

\begin{tabular}{ccc}
\hline Sample Name (n) & \multicolumn{2}{c}{$p$-Value } \\
& Normal & Weibull \\
\hline Base & 0.07 & $>0.25$ \\
iNF & 0.12 & $>0.25$ \\
sNF & 0.32 & $>0.25$ \\
\hline
\end{tabular}

Figure 4 depicts the frequency density plot of the BD events along with adjustment to normal distribution per each sample under investigation. Such a display is necessary for the detection of possible anomalies in the distribution of the AC BDV [7,23,34]. From the plots of Figure 6, along with the goodness of fit test results; it is concluded that none of them could be rejected for the following statistical analysis.

The breakdown voltages at 1, 10, and 50\% probability levels of base, iNF and sNF (Table 5) were calculated from the probability density plots for both distributions, which are demonstrated in Figure 7. The choice of these probability levels corresponds to their importance for the operation of the transformer. On the one hand, $\mathrm{U}_{50 \%}$ gives an assessment for the expected breakdown voltage, while on the other hand, $\mathrm{U}_{10 \%}$ represents an indication on the initiation threshold of ionization, and therefore assists in concluding about the reliability of the transformer oil sample [7,23,32-35]. Last but not least, the $\mathrm{BDV}$ at $1 \%$ cumulative probability is necessary information for the designing of electric equipment. $\mathrm{U}_{1 \%}$ corresponds to the limit of voltage for safety and continuous operation of the appliance [37]. 


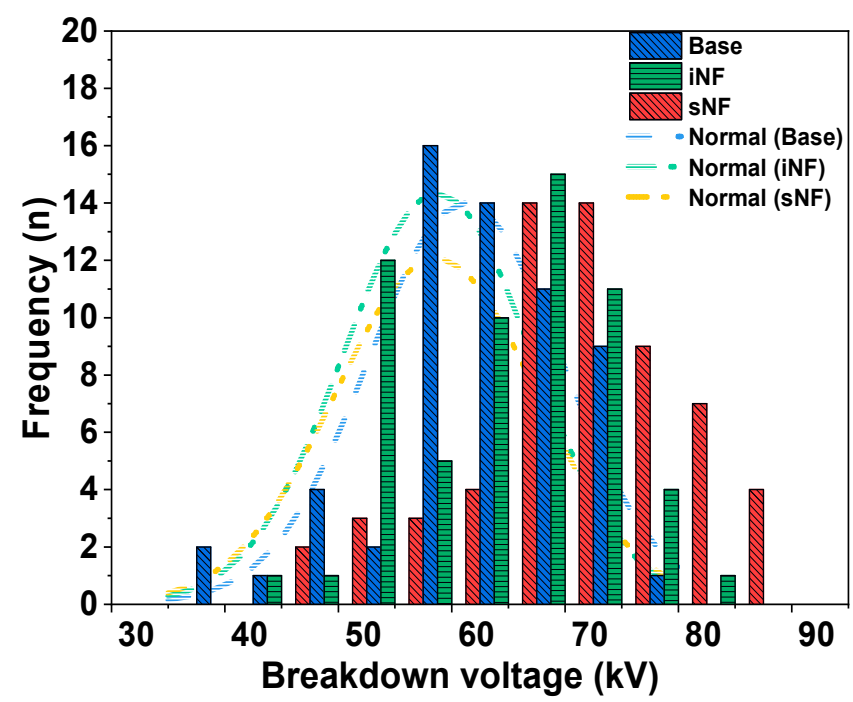

Figure 6. Frequency density plots of the breakdown events for each sample in question with conformity to Normal distribution.

Table 5. Breakdown Voltages at 1, 10 and 50\% probability levels for normal and Weibull distributions.

\begin{tabular}{ccccc}
\hline \multirow{2}{*}{ Sample Name (n) } & \multicolumn{4}{c}{ Breakdown Cumulative Probability (\%) } \\
& Distribution & $\mathbf{U}_{\mathbf{5 0}} \mathbf{( k V )}$ & $\mathbf{U}_{\mathbf{1 0} \%} \mathbf{( k V )}$ & $\mathbf{U}_{\mathbf{1} \%} \mathbf{( k V )}$ \\
\hline \multirow{2}{*}{ Base } & Normal & 61.3 & 50.3 & 41.3 \\
& Weibull & 62.2 & 50.1 & 38.6 \\
\multirow{2}{*}{ iNF } & Normal & 63.8 & 53.1 & 44.4 \\
& Weibull & 64.7 & 52.3 & 40.3 \\
\multirow{2}{*}{ SNF } & Normal & 71.3 & 58.6 & 48.2 \\
& Weibull & 72.3 & 57.9 & 43.9 \\
\hline
\end{tabular}

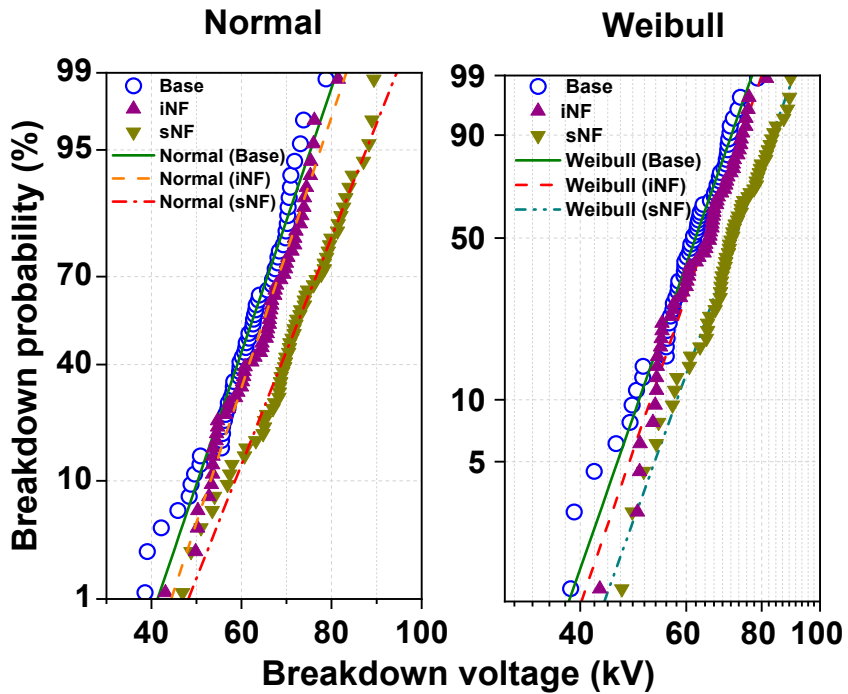

Figure 7. Probability density plots of the breakdown events for each sample in question according to Normal and Weibull distributions.

Based on the results of Table 5, both iNF and sNF demonstrate enhanced BDVs in low cumulative probability levels, with sNF showing the highest improvement with respect to the natural ester oil sample by around $16.2,15.6$, and $13.7 \%$ for $\mathrm{U}_{50 \%}, \mathrm{U}_{10 \%}$, and $\mathrm{U}_{1 \%}$, respectively. 
From the $\mathrm{U}_{10 \%}$ and $\mathrm{U}_{1 \%}$ BD probability results, it is evident that the addition of SiC NPs could assure more reliable nominal operation of the transformer and delay the initiation of streamer propagation $[23,35,37]$.

\subsection{Positive and Negative Lightning Impulse Breakdown Voltage}

The up-and-down method was implemented in order to estimate the mean LI BDV under positive and negative polarity of base oil and the two NF samples after conducting measurements in various voltage levels according to the demands of IEC 60,897 standard. The mean LI BDVs as well as the average times to breakdown are exhibited in Table 6. Figures 8 and 9 depict the oscillograms of the LI BDVs at $50 \%$ breakdown probability under positive and negative polarity, respectively.

Table 6. Mean positive and negative LI BDVs and time to breakdown.

\begin{tabular}{ccccc}
\hline Sample Name (n) & \multicolumn{2}{c}{ LI BDV (kV) } & \multicolumn{2}{c}{ Time to Breakdown $(\mu \mathrm{s})$} \\
& Positive & Negative & Positive & Negative \\
\hline Base & 73.4 & -118.7 & 16.6 & 22.3 \\
iNF & 94.3 & -120.5 & 14.8 & 15.7 \\
sNF & 77.5 & -123.4 & 15.7 & 24.2 \\
\hline
\end{tabular}

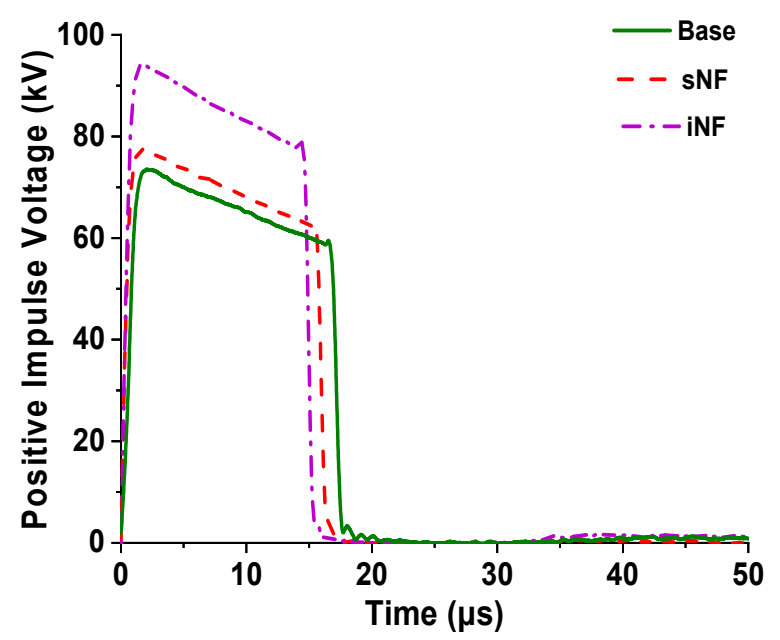

Figure 8. Oscillogram of the positive LI BDVs of the under-study samples at $50 \%$ breakdown probability level.

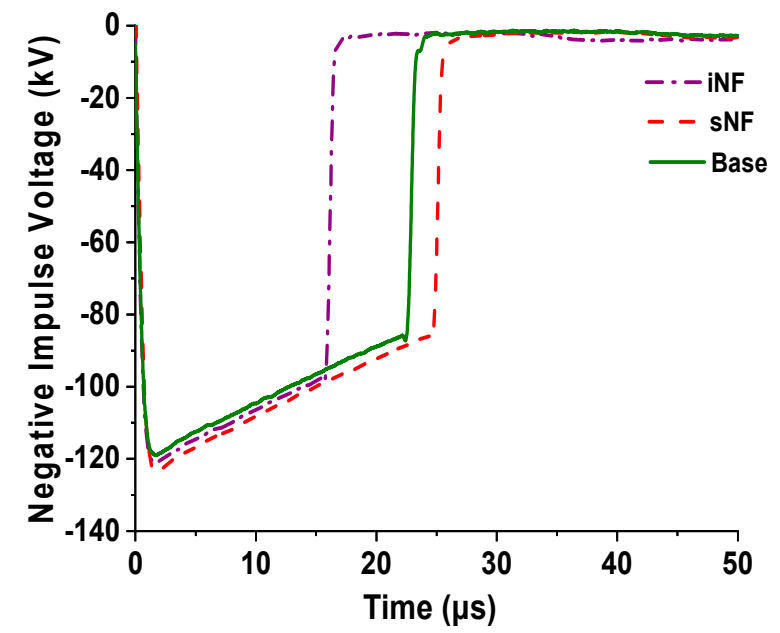

Figure 9. Oscillogram of the negative LI BDVs of the under-study samples at $50 \%$ breakdown probability level. 
The LI strength of iNF under positive polarity is enhanced by $28.5 \%$ with respect to the base oil with the corresponding improvement of sNF being limited at $6 \%$. The mean BD times of the samples after the application of positive LIV are almost steady, unlike with the corresponding ones under negative polarity. Under the application of negative LIV, the time to BD of iNF is restricted by $29.5 \%$ with respect to the one of the base oil, while sNF sample demonstrates almost the same BD time. In terms of their behavior under negative LIV, both NF samples show limited increase, as displayed in Table 6 and Figure 8. It is also evident that the addition of alumina NPs narrows the gap between positive and negative LI BDV.

\subsection{Partial Discharge}

In Figure 10, the change in apparent charge is depicted versus the applied AC voltage, while the PDIV and the value of apparent charge at the PDIV for each sample are presented in Table 7. It is evident that all the samples in question have similar behavior until about the level of $3 \mathrm{kV}$. Above this voltage level, only the paper impregnated to sNF demonstrates a stable resistance to PD activity for the whole range of AC stress, with the accumulation of apparent charge at the level of $5.5 \mathrm{kV}$ (highest applied voltage) being improved by 97.5 and $95.8 \%$ in comparison to the corresponding one of the paper impregnated to base oil and iNF, respectively. Papers impregnated to sNF and iNF samples demonstrate improved resistance to PD appearance by 92 and $44 \%$ with respect to the paper impregnated to the matrix.

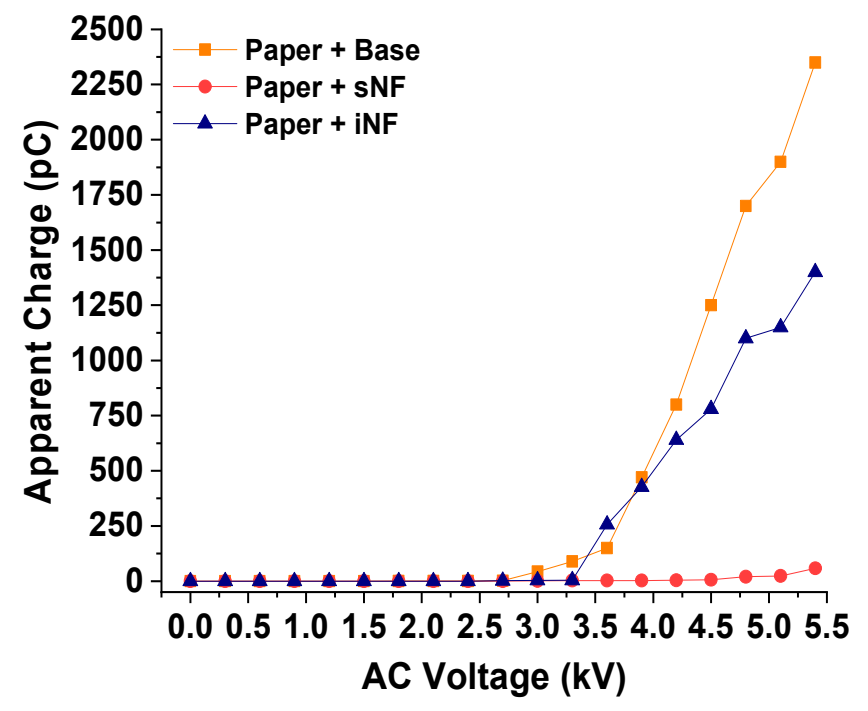

Figure 10. Change of the apparent charge as a function of the applied voltage for the three samples under investigation.

Table 7. PDIV and apparent charge at the PDIV.

\begin{tabular}{ccc}
\hline Sample Name (n) & PDIV (kV) & Apparent Charge (pC) \\
\hline Base & 2.50 & 43.1 \\
iNF & 3.60 & 257.0 \\
sNF & 4.80 & 20.0 \\
\hline
\end{tabular}

Figure 11 depicts the PD pulses related to the papers impregnated to sNF (Figure 11a) and iNF (Figure 11b) at the highest applied voltage. In the case of iNF impregnated insulating paper, the multiple pulses of irregular form indicate the presence of voids in the vicinity of the NF. 


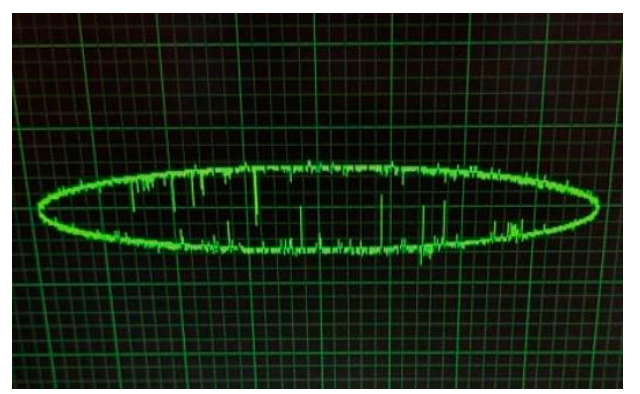

(a)

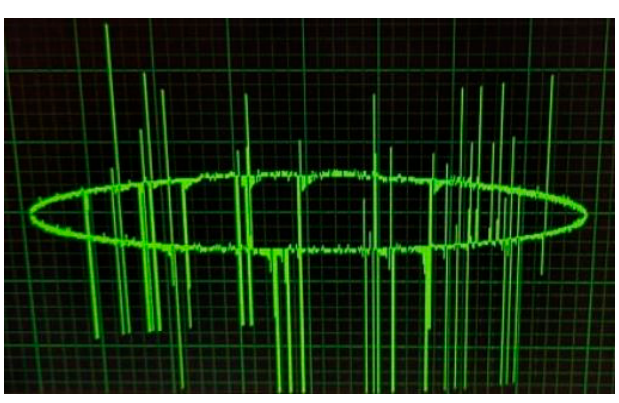

(b)

Figure 11. Waveforms of PD pulses at $5.5 \mathrm{kV}$ applied voltage: (a) Paper impregnated to sNF; (b) Paper impregnated to iNF.

\section{Discussion}

Taking into account the $\mathrm{U}_{50 \%}$ values from Table 5 according to Weibull distribution, the mean AC dielectric strength for a gap of $2.5 \mathrm{~mm}$ is $24.9 \mathrm{kV} \cdot \mathrm{mm}^{-1}, 25.9 \mathrm{kV} \cdot \mathrm{mm}^{-1}$, and $28.9 \mathrm{kV} \cdot \mathrm{mm}^{-1}$ for base, iNF, and sNF samples, respectively. This finding could be attributed to the fact that the addition of semi-conducting SiC NPs for the selected weight fraction can lead to the delay of streamer propagation, by trapping and de-trapping the fast electrons at the tip of the streamer in shallow traps $[27,28,32,38]$.

In an effort to explain the effect of the two types of NPs on BDV of the oil, Sima et al. [28] proposed a theory according to which the addition of NPs in the matrix results in change of the main electrodynamics in the dielectric liquid, regardless of their electrical properties. If considerable divergence exists in conductivity or permittivity between NP and base oil, then induced or polarized charges are generated at the interface between NP and matrix. These charges result in the production of a potential well that can trap the fast electrons at the tip of the streamer in shallow traps and slow down its propagation. As for the SiC NPs, they are characterized by much higher conductivity than that ofthe base oil, and due to their characterization as semi-conductors, charge induction involves also positive holes apart from electrons. These redistributed charges on the surface of $\mathrm{SiC}$ NPs produce a potential well, which is given by the formula [28] for the electric field direction $(\theta=0)$ and the opposite one $(\theta=\pi)$ :

$$
\varphi_{S i C}=\left\{\begin{array}{l}
\frac{\sigma_{2}-\sigma_{1}}{2 \sigma_{1}+\sigma_{2}} R^{3} E_{0} \frac{1}{r^{2}}, \theta=0, r \geq R \\
-\frac{\sigma_{2}-\sigma_{1}}{2 \sigma_{1}+\sigma_{2}} R^{3} E_{0} \frac{1}{r^{2}}, \theta=\pi, r \geq R
\end{array}\right.
$$

where $\sigma_{1}, \sigma_{2}$ are the conductivities of matrix and NPs in S. $\mathrm{m}^{-1}$, respectively, $\mathrm{R}$ is the radius of NP in $\mathrm{m}$, $E_{0}$ is the mean dielectric strength of the NF in $\mathrm{V} \cdot \mathrm{m}^{-1}$ and $\mathrm{r}$ is the distance from the NP's surface in $\mathrm{m}$.

On the other hand, surface charges, known as bound charges, are formed at the surface of dielectric alumina NPs, due to polarization under the influence of an external electric field $E_{0}$. This mechanism incorporates displacement and turning-direction polarizations. The displacement polarizations are generated very quickly in only $10^{-15}$ to $10^{-12} \mathrm{~s}$, while turning-direction polarizations in time ranging from $10^{-10} \mathrm{~s}$ to $10^{-2} \mathrm{~s}$ [28]. Therefore, they can also produce a potential well, which is given by:

$$
\varphi_{A l 2 O 3}=\left\{\begin{array}{l}
\frac{\varepsilon_{2}-\varepsilon_{1}}{2 \varepsilon_{1}+\varepsilon_{2}} R^{3} E_{0} \frac{1}{r^{2}}, \theta=0, r \geq R \\
-\frac{\varepsilon_{2}-\varepsilon_{1}}{2 \varepsilon_{1}+\varepsilon_{2}} R^{3} E_{0} \frac{1}{r^{2}}, \theta=\pi, r \geq R
\end{array}\right.
$$

where $\varepsilon_{1}, \varepsilon_{2}$ are the permittivities of matrix and NPs in F.m ${ }^{-1}$, respectively.

The potential well on each occasion is able to catch the fast-moving electrons and transform them into negatively charged NPs which are moving slowly due to their larger radius. This could lead to the delay of streamer propagation and thus higher required voltage level to bridge the gap. 
Substituting the values of conductivity and permittivity of FR3 ${ }^{\mathrm{TM}}$, $\mathrm{SiC}$ and $\mathrm{Al}_{2} \mathrm{O}_{3} \mathrm{NPs}$, as well as the corresponding values of mean dielectric strength and radius of NPs in Equations (3) and (4), the potential well of the colloidal suspensions of $\mathrm{SiC}$ and $\mathrm{Al}_{2} \mathrm{O}_{3}$ is given as:

$$
\begin{gathered}
\varphi_{\text {SiC }(r)}=3.61 \times 10^{-15} \times \frac{1}{r^{2}}[V] \\
\varphi_{A l 2 O 3(r)}=1.32 \times 10^{-15} \times \frac{1}{r^{2}}[V]
\end{gathered}
$$

Figure 12 demonstrates the higher potential well of the suspended SiC NPs in the oil, especially while moving closer to their surface. These types of NPs have the ability to capture more free electrons in shallow traps than the alumina NPs. This fact explains their increased dielectric performance. The total amount of charge that can be trapped by each of these two types of NPs is expressed by (7) and (8), respectively:

$$
\begin{gathered}
Q_{S i C}=-12 \pi \varepsilon_{1} E_{0} R^{2} \\
Q_{A l 2 O 3}=-12 \pi \varepsilon_{1} E_{0} R^{2} \frac{\varepsilon_{2}}{2 \varepsilon_{1}+\varepsilon_{2}}
\end{gathered}
$$

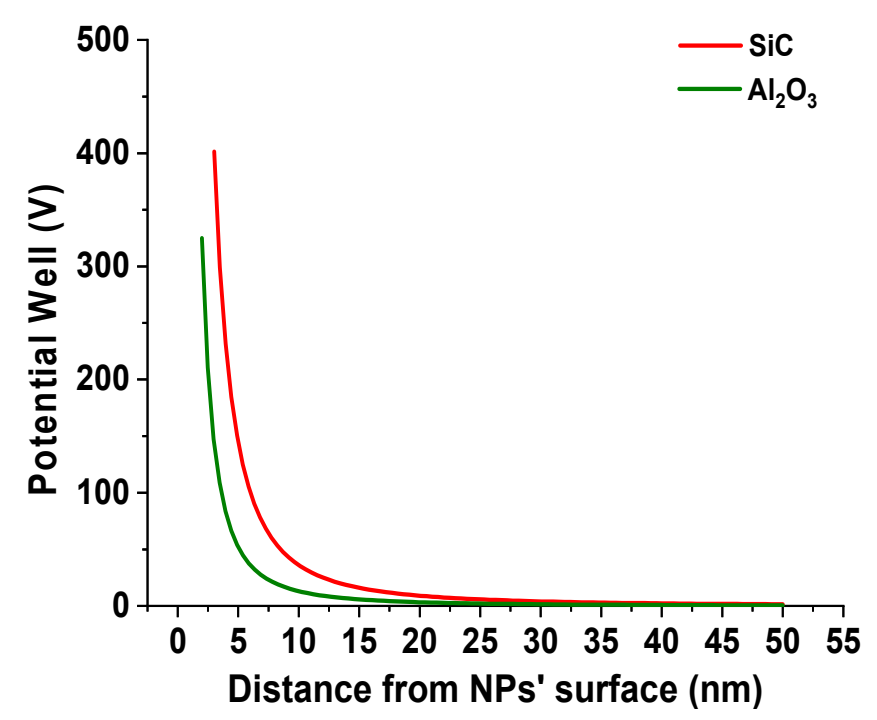

Figure 12. Potential well distribution versus the distance from the NPs' surface.

Additionally, with substitution of the corresponding values as indicated above, they give:

$$
\begin{gathered}
Q_{S i C}=-7.71 \times 10^{-17} \mathrm{C} \\
Q_{A l 2 O 3}=-4.18 \times 10^{-17} \mathrm{C}
\end{gathered}
$$

This means that each $\mathrm{SiC}$ and $\mathrm{Al}_{2} \mathrm{O}_{3} \mathrm{NP}$ could potentially capture approximately 482 and 300 electrons, respectively, until they are saturated. The higher amount of trapped charge carriers in sNF is ought to the higher conductivity of SiC NPs and is a result of the mechanism described above. Streamers propagate in different modes, which are characterized by increasing velocity. Atiya et al. [32] indicated that the operation of NPs as electron traps hinders the first two slow modes, which are applicable under AC voltage.

Unlike AC, higher streamer propagation velocities are applicable under Lightning Impulse Voltage (LIV). Ionization of the oil molecules begins above a threshold value of electric field which includes positive ions and electrons. During positive LIV, the space charge field created by the positive ions increases towards the grounded sphere, facilitating the propagation of positive streamers. Under negative polarity, the electric field towards the grounded sphere is weakened by the space 
charge field, hindering the propagation of negative streamers. This explains why negative LI BDV is higher than the positive LI BDV. Both types of NFs demonstrate increased strength under positive and negative LIV, which indicates that the trapping of high mobility electrons at the tip of the streamer in shallow traps results in increased BD performance $[2,7,39]$. However, the better performance of iNF during positive LIV and its worse performance during negative LIV with respect to sNF could be attributed to the distribution of the space charge field [39,40]. The positive charges induced by the $\mathrm{Al}_{2} \mathrm{O}_{3} \mathrm{NPs}$ can trap the fast electrons at the tip of the streamer, inhibiting its initiation and propagation towards the grounded sphere electrode. On the other hand, under negative polarity, the addition of $\mathrm{Al}_{2} \mathrm{O}_{3}$ NPs increases the electric field towards the grounded sphere, accelerating the propagation of negative streamers.

The improved resistance to PD activity of both NF samples, with respect to the base oil, can be attributed to the formation of the electrical double layer (EDL) between the surface of the NP and the oil $[3,7,32]$. The addition of these types of NPs can augment the interfacial EDL, which can capture the charge carriers and delay the initiation of PD activity. The better performance of sNF can be interpreted by the greater ability of SiC NPs to trap the charge carriers, foremost the high mobility electrons, and delay the appearance of PD in the vicinity of the liquid, as it was explained above.

\section{Conclusions}

In summary, two NF samples, containing $\mathrm{Al}_{2} \mathrm{O}_{3}$ (iNF) and $\mathrm{SiC}(\mathrm{sNF}) \mathrm{NPs}$ in the same concentration $(0.004 \% w / w)$, were synthesized and characterized. Electron microscopy showed that primary particles have a narrow particle size distribution. DLS has revealed rather good stability of the dispersion towards agglomeration over a period of five days. Both dispersions exhibit similar agglomeration behavior. AC, positive and negative LI BDV, and PD activity of the NF samples were measured and compared to the corresponding dielectric properties of a pure base oil sample. AC BDV results indicated that sNF demonstrates the highest improvement in terms of dielectric strength by $16.3 \%$. The statistical analysis also showed that the same sample demonstrates increased AC BDV by 15.6 and $13.7 \%$ at 10 and $1 \%$ probability levels, providing an indication of enhanced reliability for the uninterrupted operation of the power transformer. These findings have been attributed to the greater ability of SiC NPs to trap charge carriers in shallow traps, because of their higher conductivity.

On the other hand, the increase in positive LI BDV of iNF can be attributed to the positive charge induced by alumina NPs, which results in delaying the streamer propagation from the positive point. Finally, sNF impregnated paper also demonstrates the greatest resistance to the appearance of PD, delaying its initiation by $92 \%$ with respect to the paper impregnated to matrix. This finding could be attributed to the role of charge carriers' trapping from the augmented interfacial zone between SiC NPs and matrix. Our future research work includes an attempt to find an appropriate surface modification technique in order to achieve long-term stability of the $\mathrm{Al}_{2} \mathrm{O}_{3}$ and $\mathrm{SiC}$ dispersions, which will be followed by the conduction of measurements of dielectric and thermal properties to address the effect of surface modification on them.

Author Contributions: Conceptualization, K.N.K., I.A.N., E.C.P. and V.P.C.; methodology, K.N.K., I.A.N. and A.E.A.; validation, E.C.P., I.F.G. and S.N.Y.; formal analysis, K.N.K. and I.A.N.; investigation, K.N.K., I.A.N., E.C.P. and V.P.C.; resources, E.C.P.; data curation, I.F.G., A.E.A. and S.N.Y.; writing-original draft preparation, K.N.K. and V.P.C.; writing-review and editing, I.F.G. and S.N.Y.; supervision, E.C.P. and S.N.Y. All authors have read and agreed to the published version of the manuscript.

Funding: This research received no external funding.

Acknowledgments: Authors want to express their gratitude to Christina Polyzou of the Laboratory of Physical, Inorganic and Nuclear Chemistry, Department of Chemistry, University of Patras for the assistance in the synthesis of the NF samples.

Conflicts of Interest: The authors declare no conflict of interest. 


\section{References}

1. Hussain, M.R.; Khan, Q.; Khan, A.A.; Refaat, S.S.; Abu-Rub, H. Dielectric Performance of Magneto-Nanofluids for Advancing Oil-Immersed Power Transformer. IEEE Access 2020, 8, 163316-163328. [CrossRef]

2. Du, Y.; Lv, Y.; Li, C.; Chen, M.; Zhong, Y.; Zhou, J.; Li, X.; Zhou, Y. Effect of semiconductive nanoparticles on insulating performances of transformer oil. IEEE Trans. Dielectr. Electr. Insul. 2012, 19, 770-776.

3. Thomas, P.; Hudedmani, N.; Prasath, R.T.A.R.; Roy, N.K.; Mahato, S.N. Synthetic Ester Oil Based High Permittivity $\mathrm{CaCu}_{3} \mathrm{Ti}_{4} \mathrm{O}_{12}$ (CCTO) Nanofluids an Alternative Insulating Medium for Power Transformer. IEEE Trans. Dielectr. Electr. Insul. 2019, 26, 314-321. [CrossRef]

4. Peppas, G.D.; Charalampakos, V.P.; Pyrgioti, E.C.; Gonos, I.F. Electrical and optical measurements investigation of the pre-breakdown processes in natural ester oil under different impulse voltage waveforms. IET Sci. Meas. Technol. 2016, 10, 545-551. [CrossRef]

5. Farade, R.A.; Wahab, N.I.A.; Mansour, D.A.; Azis, N.B.; Jasni, J.; Soudagar, M.E.M.; Siddappa, V. Development of Graphene Oxide-Based Nonedible Cottonseed Nanofluids for Power Transformers. Materials 2020, 13, 2569. [CrossRef]

6. Katiyar, A.; Dhar, P.; Nandi, T.; Maganti, L.S.; Das, S.K. Enhanced Breakdown Performance of Anatase and Rutile Titania based Nanooils. IEEE Trans. Dielectr. Electr. Insul. 2016, 23, 3494-3503. [CrossRef]

7. Koutras, K.N.; Naxakis, I.A.; Antonelou, A.E.; Charalampakos, V.P.; Pyrgioti, E.C.; Yannopoulos, S.N. Dielectric strength and stability of natural ester oil based $\mathrm{TiO}_{2}$ nanofluids. J. Mol. Liq. 2020, 316, 113901. [CrossRef]

8. Zhong, Y.; Lv, Y.; Li, C.; Du, Y.; Chen, M.; Zhang, S.; Zhou, Y.; Chen, L. Insulating properties and charge characteristics of natural ester fluid modified by $\mathrm{TiO}_{2}$ semiconductive nanoparticles. IEEE Trans. Dielectr. Electr. Insul. 2013, 20, 135-140. [CrossRef]

9. Charalampakos, V.P.; Peppas, G.D.; Pyrgioti, E.C.; Bakandritsos, A.; Polykrati, A.D.; Gonos, I.F. Dielectric Insulation Characteristics of Natural Ester Fluid Modified by Colloidal Iron Oxide Ions and Silica Nanoparticles. Energies 2019, 12, 3259. [CrossRef]

10. McShane, C. New safety dielectric coolants for distribution and power transformers. IEEE Ind. Appl. Mag. 2000, 6, 24-32. [CrossRef]

11. Salama, M.M.M.; Mansour, D.A.; Daghrah, M.; Abdelkasouda, S.M.; Abbasa, A.A. Thermal performance of transformers filled with environmentally friendly oils under various loading conditions. Int. J. Electr. Power Energy Syst. 2020, 118, 105743. [CrossRef]

12. Daghrah, M.; Wang, Z.; Liu, Q.; Hilker, A.; Gyore, A. Experimental study of the influence of different liquids on the transformer cooling performance. IEEE Trans. Power Deliv. 2019, 34, 588-595. [CrossRef]

13. Ali, M.; Sahito, M.F.; Jha, N.K.; Arain, Z.U.A.; Memon, S.; Keshavarz, A.; Iglauer, S.; Saeedi, A.; Sarmadivaleh, M. Effect of nanofluid on $\mathrm{CO}_{2}$-wettability reversal of sandstone formation; implications for $\mathrm{CO}_{2}$ geo-storage. J. Colloid Interface Sci. 2020, 559, 304-312. [CrossRef] [PubMed]

14. Jha, N.K.; Lebedev, M.; Iglauer, S.; Ali, M.; Roshan, H.; Barifcani, A.; Sangwai, J.S.; Sarmadivaleh, M. Pore scale investigation of low salinity surfactant nanofluid injection into oil saturated sandstone via X-ray micro-tomography. J. Colloid Interface Sci. 2020, 562, 370-380. [CrossRef] [PubMed]

15. Al-Anssari, S.; Arain, Z.U.A.; Shanshool, H.A.; Ali, M.; Keshavarz, A.; Iglauer, S.; Sarmadivaleh, M. Effect of Nanoparticles on the Interfacial Tension of $\mathrm{CO}_{2}$-Oil System at High Pressure and Temperature: An Experimental Approach. In Proceedings of the SPE Asia Pacific Oil \& Gas Conference and Exhibition, Bali, Indonesia, 12-14 October 2020.

16. Aftab, A.; Ali, M.; Arif, M.; Panhwar, S.; Saady, N.M.C.; Al-Khdheeawi, E.A.; Mahmoud, O.; Ismail, A.R.; Kesharvaz, A.; Iglauer, S. Influence of tailor-made $\mathrm{TiO}_{2} / \mathrm{API}$ bentonite nanocomposite on drilling mud performance: Towards enhanced drilling operations. Appl. Clay Sci. 2020, 199, 105862. [CrossRef]

17. Rafiq, M.; Shafique, M.; Azam, A.; Ateeq, M. Transformer oil-based nanofluid: The application of nanomaterials on thermal, electrical and physicochemical properties of liquid insulation-A review. Ain Shams Eng. J. 2020. in Press. [CrossRef]

18. Choi, S.U.S.; Eastman, J.A. Enhancing Thermal Conductivity of Fluids with Nanoparticles. In Proceedings of the 1995 International Mechanical Engineering Congress Exposition, San Francisco, CA, USA, 12-17 November 1995; pp. 99-105. 
19. Mohamad, N.A.; Azis, N.; Jasni, J.; Ab Kadir, M.Z.A.; Yunus, R.; Yaakub, Z. Impact of $\mathrm{Fe}_{3} \mathrm{O}_{4}, \mathrm{CuO}$ and $\mathrm{Al}_{2} \mathrm{O}_{3}$ on the AC Breakdown Voltage of Palm Oil and Coconut Oil in the Presence of CTAB. Energies 2019, $12,1605$. [CrossRef]

20. Wang, X.; Xu, X.; Choi, S.U.S. Thermal conductivity of nanoparticle-fluid mixture. J. Thermophys. Heat Transf. 1999, 13, 474-480. [CrossRef]

21. Du, B.X.; Li, X.L.; Xiao, M. High Thermal Conductivity Transformer Oil Filled with BN Nanoparticles. IEEE Trans. Dielectr. Electr. Insul. 2015, 22, 851-858. [CrossRef]

22. Du, Y.; Lv, Y.; Li, C.; Chen, M.; Zhou, J.; Li, X.; Zhou, Y.; Tu, Y. Effect of electron shallow trap on breakdown performance of transformer oil-based nanofluids. J. Appl. Phys. 2011, 110, 104104. [CrossRef]

23. Khaled, U.; Beroual, A. AC Dielectric Strength of Synthetic Ester Based $\mathrm{Fe}_{3} \mathrm{O}_{4}, \mathrm{Al}_{2} \mathrm{O}_{3}$ and $\mathrm{SiO}_{2}$ Nanofluids-Conformity with Normal and Weibull Distributions. IEEE Trans. Dielectr. Electr. Insul. 2019, 26, 625-633. [CrossRef]

24. Rafiq, M.; Chengrong, L.; Lv, Y. Effect of $\mathrm{Al}_{2} \mathrm{O}_{3}$ nanorods on dielectric strength of aged transformer oil/paper insulation system. J. Mol. Liq. 2019, 284, 700-708. [CrossRef]

25. Fontes, D.H.; Ribatski, G.; Filho, E.P.B. Experimental evaluation of thermal conductivity, viscosity and breakdown voltage AC of nanofluids of carbon nanotubes and diamond in transformer oil. Diam. Relat. Mater. 2015, 58, 115-121. [CrossRef]

26. Ilyas, S.U.; Pendyala, R.; Narahari, M.; Susin, L. Stability, rheology and thermal analysis of functionalized alumina- thermal oil-based nanofluids for advanced cooling systems. Energy Convers. Manag. 2017, 142, 215-229. [CrossRef]

27. Hwang, J.G.; Zahn, M.; O'Sullivan, F.M.; Pettersson, L.A.A.; Hjortstam, O.; Liu, R. Effects of nanoparticle charging on streamer development in transformer oil-based nanofluids. J. Appl. Phys. 2010, 107, 014310. [CrossRef]

28. Sima, W.; Shi, J.; Yang, Q.; Huang, S.; Cao, X. Effects of Conductivity and Permittivity of Nanoparticle on Transformer Oil Insulation Performance: Experiment and Theory. IEEE Trans. Dielectr. Electr. Insul. 2015, 22, 380-390. [CrossRef]

29. Miao, J.; Dong, M.; Ren, M.; Wu, X.; Shen, L.; Wang, H. Effect of nanoparticle polarization on relative permittivity of transformer oil-based nanofluids. J. Appl. Phys. 2013, 113, 204103. [CrossRef]

30. Koutras, K.; Pyrgioti, E.; Naxakis, I.; Charalampakos, V.; Peppas, G. AC Breakdown Performance of $\mathrm{A1}_{2} \mathrm{O}_{3}$ and SiC Natural Ester Based Nanofluids. In Proceedings of the 2020 IEEE International Conference on Environment and Electrical Engineering and 2020 IEEE Industrial and Commercial Power Systems Europe (EEEIC/I\&CPS Europe), Madrid, Spain, 9-12 June 2020; pp. 1-5.

31. Peppas, G.D.; Charalampakos, V.P.; Pyrgioti, E.C.; Danikas, M.G.; Bakandritsos, A.; Gonos, I.F. Statistical investigation of AC breakdown voltage of nanofluids compared with mineral and natural ester oil. IET Sci. Meas. Technol. 2016, 10, 644-652. [CrossRef]

32. Atiya, E.G.; Mansour, D.A.; Khattab, R.M. Dispersion behavior and breakdown strength of transformer oil filled with $\mathrm{TiO}_{2}$ nanoparticles. IEEE Trans. Dielectr. Electr. Insul. 2015, 22, 2463-2472. [CrossRef]

33. Pyrgioti, E.C.; Koutras, K.N.; Charalampakos, V.P.; Peppas, G.D.; Bakandritsos, A.P.; Naxakis, I.A. An experimental study on the influence of surface modification of $\mathrm{TiO}_{2}$ nanoparticles on breakdown voltage of natural ester nanofluid. Lect. Notes Electr. Eng. 2020, 599, 279-288.

34. Martin, D.; Wang, Z.D. Statistical analysis of the AC breakdown voltages of ester based transformer oils. IEEE Trans. Dielectr. Electr. Insul. 2008, 15, 1044-1050. [CrossRef]

35. Khaled, U.; Beroual, A. AC dielectric strength of mineral oil-based $\mathrm{Fe}_{3} \mathrm{O}_{4}$ and $\mathrm{Al}_{2} \mathrm{O}_{3}$ nanofluids. Energies 2018, 11, 3505. [CrossRef]

36. Dang, V.-H.; Beroual, A.; Perrier, C. Comparative study of statistical breakdown in mineral, synthetic and natural ester oils under AC voltage. IEEE Trans. Dielectr. Electr. Insul. 2012, 19, 1508-1513. [CrossRef]

37. Khaled, U.; Beroual, A. Statistical Investigation of AC Breakdown Voltage of Natural Ester with Electronic Scavenger Additives. IEEE Trans. Dielectr. Electr. Insul. 2019, 26, 2012-2018. [CrossRef]

38. Li, J.; Zhang, Z.; Zou, P.; Grzybowski, S.; Zahn, M. Preparation of a vegetable oil-based nanofluid and investigation of its breakdown and dielectric properties. IEEE Electr. Insul. Mag. 2012, 28, 43-50. [CrossRef]

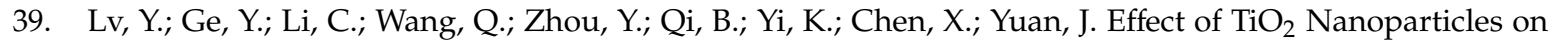
Streamer Propagation in Transformer Oil under Lightning Impulse Voltage. IEEE Trans. Dielectr. Electr. Insul. 2016, 23, 2110-2115. [CrossRef] 
40. Massala, G.; Lesaint, O. Positive streamer propagation in large oil gaps: Electrical properties of streamers. IEEE Trans. Dielectr. Electr. Insul. 1998, 5, 371-381. [CrossRef]

Publisher's Note: MDPI stays neutral with regard to jurisdictional claims in published maps and institutional affiliations.

(C) 2020 by the authors. Licensee MDPI, Basel, Switzerland. This article is an open access article distributed under the terms and conditions of the Creative Commons Attribution (CC BY) license (http://creativecommons.org/licenses/by/4.0/). 